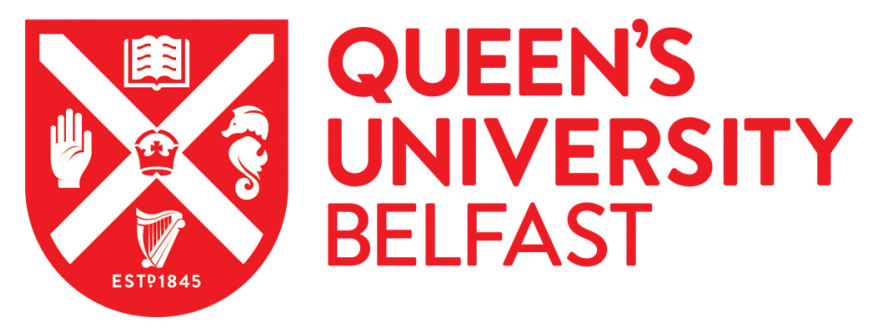

\title{
What is the prevalence of Autism Spectrum Disorder and ASD traits in psychosis? A systematic review
}

Kincaid, D., Doris, M., Shannon, C., \& Mulholland, C. (2017). What is the prevalence of Autism Spectrum Disorder and ASD traits in psychosis? A systematic review. Psychiatry Research.

https://doi.org/10.1016/j.psychres.2017.01.017

Published in:

Psychiatry Research

Document Version:

Peer reviewed version

Queen's University Belfast - Research Portal:

Link to publication record in Queen's University Belfast Research Portal

Publisher rights

Copyright $\odot 2017$ Elsevier B.V. This manuscript version is made available under the CC-BY-NC-ND 4.0 license

http://creativecommons.org/licenses/by-nc-nd/4.0/ which permits distribution and reproduction for non-commercial purposes, provided the author and source are cited.

\section{General rights}

Copyright for the publications made accessible via the Queen's University Belfast Research Portal is retained by the author(s) and / or other copyright owners and it is a condition of accessing these publications that users recognise and abide by the legal requirements associated with these rights.

Take down policy

The Research Portal is Queen's institutional repository that provides access to Queen's research output. Every effort has been made to ensure that content in the Research Portal does not infringe any person's rights, or applicable UK laws. If you discover content in the Research Portal that you believe breaches copyright or violates any law, please contact openaccess@qub.ac.uk. 


\section{Author's Accepted Manuscript}

What is the prevalence of Autism Spectrum Disorder and ASD traits in psychosis? A systematic review

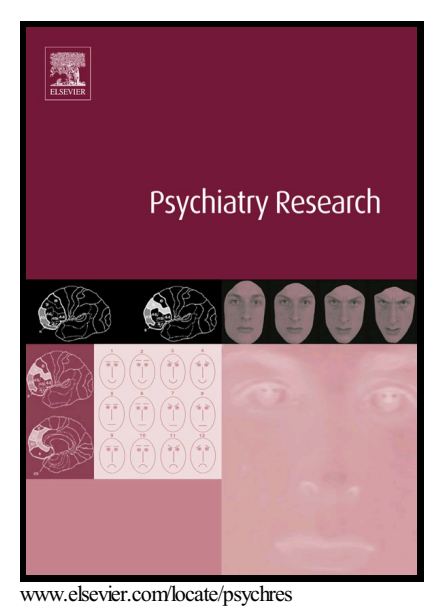

Debbie L. Kincaid, Michael Doris, Ciaran Shannon, Ciaran Mulholland

PII: $\quad$ S0165-1781(16)31418-4

DOI: $\quad$ http://dx.doi.org/10.1016/j.psychres.2017.01.017

Reference: PSY10212

To appear in: Psychiatry Research

Received date: 23 August 2016

Revised date: 15 December 2016

Accepted date: 6 January 2017

Cite this article as: Debbie L. Kincaid, Michael Doris, Ciaran Shannon an Ciaran Mulholland, What is the prevalence of Autism Spectrum Disorder anc ASD traits in psychosis? A systematic review, Psychiatry Research http://dx.doi.org/10.1016/j.psychres.2017.01.017

This is a PDF file of an unedited manuscript that has been accepted fo publication. As a service to our customers we are providing this early version o the manuscript. The manuscript will undergo copyediting, typesetting, an review of the resulting galley proof before it is published in its final citable form Please note that during the production process errors may be discovered whic could affect the content, and all legal disclaimers that apply to the journal pertain 


\title{
What is the prevalence of Autism Spectrum Disorder and ASD traits in psychosis? A
}

\section{systematic review}

\author{
Dr Debbie L. Kincaid ${ }^{\mathrm{a}^{*}}$, Dr Michael Doris ${ }^{\mathrm{b}}$, Dr Ciaran Shannon ${ }^{\mathrm{a}}, \&$ Prof Ciaran Mulholland ${ }^{\mathrm{b}}$ \\ ${ }^{a}$ School of Psychology, The Queen's University of Belfast, Belfast, Northern Ireland \\ ${ }^{\mathrm{b}}$ Northern Health and Social Care Trust, Antrim, Northern Ireland
}

*Corresponding Author: Dr Debbie Kincaid, School of Psychology, Queen's University Belfast, David Keir Building, 18-30 Malone Road, Belfast, BT9 5BP. Telephone: 02890974283. Email: dscroggie03@qub.ac.uk

\section{Abstract}

There is increasing evidence to suggest both a symptomatic overlap and a clinically significant degree of co-occurrence between Autism Spectrum Disorders (ASD) and psychotic disorders such as schizophrenia but the nature of such relationships remain unclear. We reviewed the literature reporting prevalence rates of Autistic-like Traits (ALTs) and ASD in populations with a diagnosis of schizophrenia or other psychotic disorder. A search of three large databases was conducted and from this seven studies met the criteria for inclusion. The point prevalence rates for ALTs ranged from $9.6 \%$ to $61 \%$, whilst the prevalence rates for diagnosed ASD ranged from $<1 \%$ to $52 \%$ across outpatient and inpatient populations. This suggests that prevalence rates of 
ALTs and ASD in psychosis populations are much higher than in the general population. This has important implications regarding future research, and clinical implications in terms of ensuring that patients receive the most appropriate diagnosis and treatment.

Keywords

Schizophrenia, Autism, Asperger's, Co-morbid, co-occur.

\section{Introduction}

In recent years there has been increasing interest in the relationship between psychotic symptoms, psychotic disorders (such as schizophrenia), and symptoms consistent with Autism Spectrum Disorders (ASD). Historically there was much confusion in this field. A century ago, Bleuler considered "autism" to be one of the four core symptoms of schizophrenia (Askok et al., 2012). In the middle part of the twentieth century, the terms schizophrenia and autism were often used synonymously in childhood. It was not until the 1970's that Kolvin (1971) and Rutter (1972) clearly defined ASD and childhood schizophrenia as separate disorders (Chisholm et al., 2015). They remain classified as separate constructs within current diagnostic classification systems.

ASD is a childhood-onset developmental disorder and its diagnosis is dependent upon evidence of impairments in social communication and social interactions, in addition to persistent restricted, repetitive patterns of behaviour or interests. Publication of the fifth edition of the Diagnostic and Statistical Manual of Mental Disorders (DSM-5) has seen previously distinct subtypes of ASD such as Asperger's Syndrome (AS) subsumed within the category of ASD, 
under neuro-developmental disorders. The prevalence of ASD is estimated to be approximately one percent of the population (Brugha et al., 2011) and it is well documented that individuals with a diagnosis of ASD are predisposed to a variety of other mental health difficulties and comorbidities.

The population prevalence of schizophrenia is estimated to be one percent (Bradley et al., 2011) and ASD may present a risk factor for the development of schizophrenia (Nylander et al., 2008). DSM-5 and International Classification of Diseases (ICD-10) criteria for schizophrenia relate to the presence of two of more of the following symptoms: hallucinations, delusions, disorganised speech, disorganised (or catatonic) behaviour, and negative symptoms, present for a significant duration throughout a one month period. Where there is childhood onset of ASD or another communication disorder, a DSM-5 diagnosis of schizophrenia will only be made if there is evidence of prominent hallucinations or delusions for at least one month.

ASD and schizophrenia are both characterised by atypical neurodevelopment of language and difficulties with social interaction and communication; however, individuals diagnosed with Asperger's Syndrome (AS) as per the DSM-IV classification system by definition do not have significant delay in language or cognitive development (Davidson et al., 2014: Raja \& Azonni, 2001; Solomon et al., 2011). The impairments in social functioning common to both presentations may be underpinned by overlapping psychological mechanisms such as Theory of 
Mind (ToM) impairments, which though a feature of both disorders, are not identified in current diagnostic criteria (Chisholm et al., 2015).

ASD symptoms appear to overlap most significantly with negative symptoms of schizophrenia. For example, difficulties with emotional reciprocity, or speech delay or absence observed in ASD may be understood in terms of blunting of affect or alogia (poverty of speech) in schizophrenia, respectively. Catatonic features may also present in both disorders. Phenotypic similarities can therefore result in difficulties with differential diagnosis according to classification systems such as the DSM which are based upon observation of specified clinical symptoms. Conversely, positive symptoms such as hallucinations and delusions are defining features of schizophrenia but are not typically symptomatic of ASD. Age of onset constitutes another significant distinction between the two constructs (Konstantareas \& Hewitt, 2001).

Whilst there is some evidence to suggest that ASD and schizophrenia co-occur at elevated rates, there is a lack of systematic research on the co-occurrence of these two disorders (Chisholm et al., 2015; Davidson et al., 2014; del Real et al., 2010). A systematic review attempting to ascertain the prevalence rates of psychosis, anxiety and affective disorders in ASD populations reported prevalence rates of schizophrenia between $0 \%$ and $6 \%$. Comparison across studies was complicated by substantial methodological heterogeneity and some of the included studies reported on prevalence rates in child and adolescent populations and therefore may have underestimated the prevalence of symptoms yet to emerge (Skokauskas \& Gallagher, 2010). A similar systematic review reported difficulties in drawing accurate conclusions about the co- 
occurrence of psychosis and Pervasive Developmental Disorders (PDD) due to methodological variation, heterogeneity and issues of selection bias. The authors highlighted the importance of future research in order to understand the potential mechanisms underpinning their co-morbidity (Padgett et al., 2010). There is no published research known to the authors which systematically reviews the prevalence of ASD in adult psychosis populations. It should be acknowledged however, that there have been a number of studies which have explored the relationship between childhood-onset schizophrenia and ASD. A longitudinal study carried out by the National Institute of Mental Health (NIMH) in 2004 found that $25 \%$ of 75 children with a diagnosis of childhood-onset schizophrenia had a lifetime diagnosis of ASD: one met criteria for autism, two for AS, and 16 for Pervasive Developmental Disorder Not Otherwise Specified (PDD-NOS) (Sporn et al., 2004). This result was replicated with a larger sample size of 101, showing a similar proportion (28\%) with a lifetime diagnosis of ASD (Rapoport et al., 2009). A study carried out by Hallerbäck and colleagues (2012) in a Swedish population of patients with a Schizophreniform illness found that $41 \%$ met diagnostic criteria for ASD based upon interviews carried out with their parents, with particular focus on the presence of ASD symptomatology in childhood and adolescence.

The present review therefore aims to assimilate all published studies reporting such prevalence rates. The literature pertaining to both psychosis and ASD is primarily diagnostically based at present therefore this review will explore prevalence rates in accordance with the relevant diagnostic categories. Furthermore, as both disorders are proposed to exist on a continuum of severity, it is important to consider not only the prevalence of diagnosed ASD, but also "subthreshold" ASD symptoms or traits referred to hereafter as Autistic-like Traits (ALTs). ALTs 
include symptoms consistent with the diagnostic symptom profile for ASD as measured by quantitative ASD symptom scales or concurrence with diagnostic criteria. Importantly, ALTs refer to the presence of ASD symptoms at the time of assessment but may lack evidence or assessment of their presence in childhood, which is essential for a diagnosis of ASD. It is these (often overlapping) traits which form the essential criteria for diagnosis therefore this review may represent a first step in untangling a complex relationship between two overlapping constructs. Understanding the prevalence rate of ALTs and ASD in psychosis populations is an important step towards further understanding the overlaps and distinctions between the constructs, which has significant implications for both psychological and pharmacological interventions, in addition to diagnosis and policy (Chisholm et al., 2015; Mandell et al., 2012).

\section{Methods}

Studies were identified through searches of three large electronic databases: PsychINFO, Web of Science and PubMed. No date restrictions were imposed and the search strategy included the following groups of keywords: (a) schizo*, psychos*, psychot* OR delusion*; (b) ASD, asperger* OR autis*; (c) prevalence OR co-morbid*. These groups were then combined using the Boolean operator AND. The systematic literature search was conducted independently by two reviewers on the $4^{\text {th }}$ December 2015 .

Studies were considered eligible for inclusion if they fulfilled the following criteria: included participants with a psychotic disorder and details of how this was assessed or classified; provided details on assessment of ASD (or ALTs) and outcomes; prevalence rates of ASD (or ALTs) 
specified (or discernable from the available information); and published in English, in a peerreviewed journal. Studies were excluded if all participants were from either an ASD population or an Intellectual Disability (ID) population as ASD is known to co-occur at a higher rate with ID (Brugha et al., 2011).

Studies were reviewed in accordance with the PRISMA Statement (Moher et al., 2009). Studies were identified for inclusion and reference lists of included studies were reviewed independently by two reviewers (DK \& MD). Both reviewers assessed the quality of articles included in the review and extracted pertinent data including study design and setting, sample demographics, details of psychosis and ASD variables, prevalence rates, and conclusions. Any disagreement was resolved through discussion or by contacting authors for additional details. A narrative synthesis of studies was undertaken due to the variability in the measurement of variables.

\section{Results}

The database search identified 1388 records and of these, 324 were removed due to duplication. The remaining 1064 records were screened by title and abstract. Sixteen potential studies for inclusion were subsequently identified therefore full text articles were sought and eligibility was assessed. Of these, seven studies met the criteria and were included in the review. Review of the reference lists did not yield any additional relevant studies. Figure 1 provides an overview of the review process. 


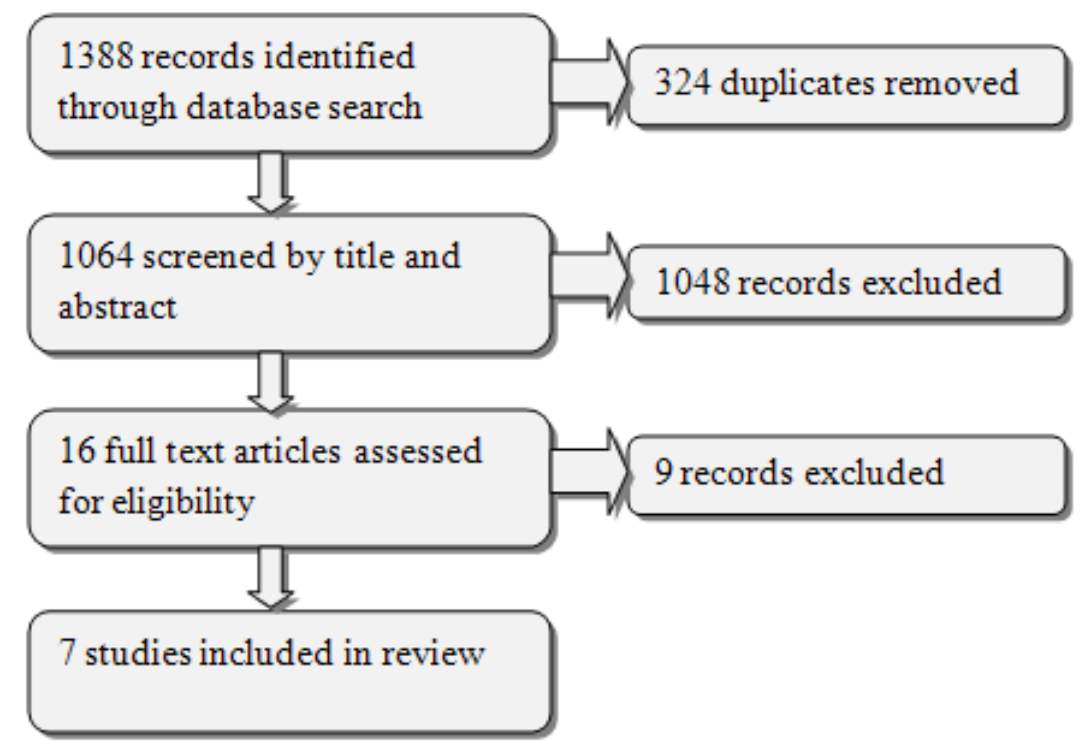

Figure 1. Flowchart detailing the systematic review process

Of the nine excluded full-text articles, two studies had duplicate samples (therefore the most recent publication was included in the review) and one study included participants who did not clearly fit a schizophrenia diagnosis. The prevalence rate was not specified or discernable for three studies (and details were not obtainable despite contacting authors). The findings of two studies related to an ID sample, whilst another study reported prevalence of co-morbidity in an ASD population. The level of agreement between reviewers was high, as evidenced by a weighted Kappa rating of 0.90 . Table 1 provides a summary of the studies included in the review. 
Table 1: Study Characteristics

\begin{tabular}{|c|c|c|c|c|c|c|c|}
\hline Authors & $\begin{array}{l}\text { Setting \& } \\
\text { Location }\end{array}$ & $\begin{array}{l}\text { Psychosis } \\
\text { Sample } \\
\text { Size }[\& \\
\text { Total } \\
\text { Sample } \\
\text { Size] } \\
\end{array}$ & $\begin{array}{l}\begin{array}{l}\text { Age } \\
\text { Range } \\
\text { of }\end{array} \\
\text { Total } \\
\text { Sample } \\
\text { (Years) } \\
\end{array}$ & $\begin{array}{l}\text { Gender } \\
\text { of total } \\
\text { study } \\
(\%)\end{array}$ & $\begin{array}{l}\text { Psychosis Diagnosis } \\
\text { \& Classification }\end{array}$ & $\begin{array}{l}\text { ASD Variable } \\
\& \\
\text { Classification }\end{array}$ & $\begin{array}{l}\text { ID (IQ } \\
<70 \text { in } \\
\text { Total } \\
\text { Sample) } \\
(\%)\end{array}$ \\
\hline $\begin{array}{l}\text { Matsuo et } \\
\text { al. (2015) }\end{array}$ & $\begin{array}{l}\text { Hospital/ } \\
\text { Clinic } \\
\text { Outpatients, } \\
\text { Japan }\end{array}$ & $\begin{array}{l}44 \\
{[290]}\end{array}$ & $25-59$ & $\begin{array}{l}46 \\
\text { Male } \\
54 \\
\text { Female }\end{array}$ & $\begin{array}{l}\text { Schizophrenia } \\
D S M-I V-T R\end{array}$ & $\begin{array}{l}\text { ALTs } \\
\text { SRS-A }\end{array}$ & 0 \\
\hline $\begin{array}{l}\text { Davidson } \\
\text { et al. } \\
\text { (2014) }\end{array}$ & $\begin{array}{l}\text { Early } \\
\text { Intervention in } \\
\text { Psychosis } \\
\text { Service, } \\
\text { England } \\
\text { (Predominantly } \\
\text { outpatients) }\end{array}$ & 197 & $14-35$ & $\begin{array}{l}57 \\
\text { Male } \\
43 \\
\text { Female }\end{array}$ & $\begin{array}{l}\text { Psychotic Disorder } \\
\text { ICD-10 }\end{array}$ & $\begin{array}{l}\text { AS } \\
D S M-I V \& \\
A S D A S Q\end{array}$ & 0 \\
\hline $\begin{array}{l}\text { Waris et } \\
\text { al. (2013) }\end{array}$ & $\begin{array}{l}\text { Psychiatric } \\
\text { Rehabilitation } \\
\text { Unit Inpatients, } \\
\text { Finland }\end{array}$ & 18 & $13-17$ & $\begin{array}{l}39 \\
\text { Male } \\
61 \\
\text { Female }\end{array}$ & $\begin{array}{l}\text { Schizophrenia } \\
D S M-I V\end{array}$ & $\begin{array}{l}\text { AS } \\
\text { DISCO } 11\end{array}$ & 0 \\
\hline $\begin{array}{l}\text { Mandell et } \\
\text { al. (2012) }\end{array}$ & $\begin{array}{l}\text { Psychiatric } \\
\text { Hospital } \\
\text { Inpatients, } \\
\text { USA }\end{array}$ & $\begin{array}{l}123 \\
{[141]}\end{array}$ & $26-82$ & $\begin{array}{l}68.8 \\
\text { Male } \\
31.2 \\
\text { Female }\end{array}$ & $\begin{array}{l}\text { Schizophrenia } \\
\text { SAPS \& SANS }\end{array}$ & $\begin{array}{l}\text { ASD } \\
A D I-R \& S R S\end{array}$ & $32.6 \%$ \\
\hline $\begin{array}{l}\text { Hallerback } \\
\text { et al. } \\
(2012)\end{array}$ & $\begin{array}{l}\text { Psychiatric } \\
\text { Clinic } \\
\text { Outpatients, } \\
\text { Sweden }\end{array}$ & $\begin{array}{l}42 \\
{[46]}\end{array}$ & $\begin{array}{l}- \\
\text { (Mean } \\
28.3 \\
\text { SD 4.7) }\end{array}$ & $\begin{array}{l}63 \\
\text { Male } \\
37 \\
\text { Female }\end{array}$ & $\begin{array}{l}\text { Schizophrenia, } \\
\text { Schizophreniform } \\
\text { Disorder or } \\
\text { Schizoaffective } \\
\text { Disorder } \\
D S M-I V\end{array}$ & $\begin{array}{l}\text { ASD } \\
D I S C O 11 \& \\
A Q\end{array}$ & 0 \\
\hline $\begin{array}{l}\text { Fraser et } \\
\text { al. }(2012)\end{array}$ & $\begin{array}{l}\text { Youth Mental } \\
\text { Health Service } \\
\text { Outpatients, } \\
\text { Australia }\end{array}$ & $\begin{array}{l}292 \\
{[476]}\end{array}$ & $15-25$ & N/A & $\begin{array}{l}\text { Psychotic Disorder } \\
D S M-I V\end{array}$ & $\begin{array}{l}\text { AS, Autistic } \\
\text { Disorder \& } \\
\text { ALTs } \\
D S M-I V\end{array}$ & - \\
\hline $\begin{array}{l}\text { Chang et } \\
\text { al. }(2003)\end{array}$ & $\begin{array}{l}\text { Psychiatric } \\
\text { Clinic } \\
\text { Outpatients, } \\
\text { Taiwan }\end{array}$ & $\begin{array}{l}128 \\
{[660]}\end{array}$ & $15-93$ & $\begin{array}{l}57 \\
\text { Male } \\
43 \\
\text { Female } \\
\end{array}$ & $\begin{array}{l}\text { Schizophrenia } \\
D S M-I V\end{array}$ & $\begin{array}{l}\text { ASD } \\
D S M-I V \& \\
A S D A S Q\end{array}$ & $\begin{array}{l}\geq 0.76 \% \\
*\end{array}$ \\
\hline $\begin{array}{l}\text { ASD: Autisn } \\
\text { Fourth Editic } \\
\text { Classificatio } \\
\text { Questionnair } \\
\text { Assessment } \\
\text { Interview- R }\end{array}$ & $\begin{array}{l}\text { Spectrum Disorder; } \\
\text { n, Text Revision; AI } \\
\text { of Diseases Version } \\
\text { f DISCO-11: Diagn } \\
\text { f Positive Symptom } \\
\text { vised; AQ: Autism }\end{array}$ & $\begin{array}{l}\text { ID: Intellectl } \\
\text { Ts: Autistic- } \\
\text { 10; AS: Asp } \\
\text { stic Intervie } \\
\text {; SANS: Sca } \\
\text { Quotient. }\end{array}$ & $\begin{array}{l}\text { al Disability; } \\
\text { ike Traits; SI } \\
\text { rger's Syndr } \\
\text { for Social a } \\
\text { for the Ass }\end{array}$ & $\begin{array}{l}\text {; DSM-IV: } \\
\text { RS-A: Soci } \\
\text { lrome; ASD } \\
\text { and Commu } \\
\text { sessment of }\end{array}$ & $\begin{array}{l}\text { Diagnostic and Statistic } \\
\text { l Responsiveness Scale } \\
\text { ASQ: Autism Spectrum } \\
\text { hication Disorders Vers } \\
\text { Negative Symptoms; A }\end{array}$ & $\begin{array}{l}\text { Manual of Mental } \\
\text { r Adults; ICD- } 10 \\
\text { sorder in Adults } \\
11 \text {; SAPS: Scale } \\
\text {-R: Autism Diagn }\end{array}$ & $\begin{array}{l}\text { sorders, } \\
\text { ternational } \\
\text { eening } \\
\text { the } \\
\text { ic }\end{array}$ \\
\hline
\end{tabular}


Each of the seven studies included in the review were conducted in a different country, spanning the continents of Europe, North America, Australia and Asia. All studies were of a crosssectional design, and included participants who had a confirmed diagnosis of schizophrenia or other psychotic disorder. Each study assessed ASD symptoms however there was variability among studies in terms of how this was assessed. Four studies used both screening and diagnostic assessments of ASD (Davidson et al., 2014, Mandell et al., 2013, Hallerback et al., 2012 and Chang et al., 2003), whilst Waris and colleagues (2013) utilised diagnostic interview only. Matsuo et al. (2015) employed a screening measure only, whereas Fraser et al. (2012) reported on existing ASD diagnoses previously confirmed by appropriate healthcare professionals, in addition to clinician opinion according to DSM-IV criteria. Study samples were primarily from outpatient populations with the exception of Waris et al. (2013) and Mandell et al. (2012) who reported on inpatients (See Table 1 for additional details).

The sample demographics (age range and gender) presented in Table 1 relate to the total sample included in each study, rather than the psychosis sample utilised by this review. Similarly, the ID data presented in Table 1 relates to the total psychiatric sample and not specifically the psychosis sample. Mandell et al. (2012) and Chang et al. (2003) were the only studies who included participants with an ID (as defined by an IQ score of less than 70). ID was an exclusion criterion for most other studies however data relating to IQ was not collected by Fraser et al. (2012). 
Table 2: Overview of results

\begin{tabular}{|c|c|c|c|c|}
\hline Authors & $\begin{array}{l}\text { Quality } \\
\text { Score }\end{array}$ & $\begin{array}{c}\text { Prior ASD } \\
\text { Diagnosis and } \\
\text { classification }\end{array}$ & $\begin{array}{c}\text { Prevalence of } \\
\text { ALTs }\end{array}$ & $\begin{array}{c}\text { Prevalence of } \\
\text { Diagnosed ASD }\end{array}$ \\
\hline $\begin{array}{l}\text { Matsuo et al. } \\
\text { (2015) }\end{array}$ & $16 / 18$ & $0 \%$ & $61 \%$ & - \\
\hline $\begin{array}{l}\text { Davidson et al. } \\
\text { (2014) }\end{array}$ & $17 / 18$ & $\begin{array}{c}1.5 \% \text { AS } \\
0.5 \% \text { HFA }\end{array}$ & $10.7 \%$ & $3.6 \% \mathrm{AS}$ \\
\hline $\begin{array}{l}\text { Waris et al. } \\
\text { (2013) }\end{array}$ & $15 / 18$ & $5.5 \%$ PDD & $56 \%$ & $\begin{array}{c}11.1 \% \text { AS; } \\
\text { 5.6\% PDD-NOS }\end{array}$ \\
\hline $\begin{array}{l}\text { Mandell et al. } \\
\text { (2013) }\end{array}$ & $16 / 18$ & $0 \%$ & - & 9.8\% ASD \\
\hline $\begin{array}{l}\text { Hallerback et al. } \\
\text { (2012) }\end{array}$ & $16 / 18$ & - & - & $52 \%$ ASD \\
\hline $\begin{array}{l}\text { Fraser et al. } \\
\text { (2012) }\end{array}$ & $14 / 18$ & $3.4 \%$ ASD & $9.6 \%$ & $3.4 \%$ ASD \\
\hline $\begin{array}{l}\text { Chang et al. } \\
\text { (2003) }\end{array}$ & $13 / 18$ & $0.8 \%$ ASD & $18.8 \%$ & 0.78\% ASD \\
\hline
\end{tabular}

The prevalence rates of diagnosed ASDs were reported for all studies with the exception of Matsuo et al. (2015). These rates ranged from $0.78 \%$ to $52 \%$, and related predominately to ASD but also included AS and PDD-NOS subcategories. Details of the prevalence of ALTs or ASD symptoms which did not meet the criteria for diagnosis were available from most of the studies except Mandell et al. (2013) and Hallerback et al. (2012). Again, there was considerable variation in the observed rates which ranged from $9.6 \%$ to $61 \%$.

Four studies provided details on existing diagnoses of ASD prior to inclusion in their study (Davidson et al., 2014, Waris et al., 2013, Fraser et al., 2012 and Chang et al., 2003) and in two cases the number of individuals who received a diagnosis of ASD increased (Davidson et al., 
2014; Waris et al., 2013). Matsuo et al. (2015) excluded individuals with an existing diagnosis of ASD, and whilst Mandell et al. (2013) did not impose this as an exclusion criterion, nearly a tenth of their participants received a diagnosis of ASD despite no pre-existing diagnoses. Hallerback et al. (2012) did not report on this despite the researcher attempting to make contact with the author. See table 2 for further information. Interestingly, Hallerback et al. (2012) was the only study to investigate potential relationships between subtypes of ASD and subtypes of schizophrenia. Their results demonstrated the highest rate of ASD (60\%) co-occurring within the 'paranoid schizophrenia' subgroup.

Quality assessment

The quality of studies was assessed through discussion by both reviewers in accordance with the assessment criteria delineated by Kmet et al. (2004). Criteria 5-7 were omitted as these related to interventional studies, as were criteria 11-12 as these referred to analyses not relevant to prevalence studies. Table 2 provides details of the quality assessment scores, alongside prevalence rates of ALTs and ASD reported by each study. The studies included in the review were considered to be of fair-to-high quality. There was a clear rationale provided for each study, and each author's conclusions were supported by their outcomes. All-but-two studies used reliable and valid diagnostic criteria and subsequent interview instruments to confirm a diagnosis of schizophrenia or other psychotic disorder: Fraser et al. (2012) used DSM-IV criteria however did not employ a diagnostic interview, whilst Chang et al. (2003) also used DSM-IV criteria for schizophrenia however did not provide details of how this was assessed. 
There was a high degree of methodological variation in the measurement of ASD symptoms; however, the highest-rated studies tended to be those who employed both screening and diagnostic assessments of ASD (Davidson et al., 2014, Mandell et al., 2012, Hallerback et al., 2012). Three quantitative measures of ASD symptoms were used across five studies. The Social Responsiveness Scale for Adults (SRS-A) was used by Mandell et al. (2012) and Matsuo et al. (2015). It has sufficient sensitivity and specificity for adult populations however there is a lack of data on reliability in a psychosis population. Mandell et al. (2012) did not report sufficient details to enable calculation of the prevalence of ALTs in their sample as they claimed that it did not have sufficient specificity (for assessing ASD at the diagnostic level) in their sample of predominantly long-stay in-patients with complex needs. The Autism Spectrum Disorder in Adults Screening Questionnaire (ASDASQ) was used for screening by Chang et al. (2003) and Davidson et al. (2014), the latter of whom suggested that the Gillberg criteria on which it is based may be superior to the DSM-IV or ICD-10 criteria. The authors of this measure report good psychometric properties including high levels of internal consistency, fair-to-moderate testretest reliability and inter-rater reliability, in addition to high specificity and sensitivity (Nylander \& Gillberg, 2001). The aforementioned measures were all completed by individuals known to the patient such as family or healthcare professionals. Hallerback et al. (2012) was the only study to use a self-report measure, namely the Autism Quotient (AQ), as a screening tool for autistic traits but did not report on the outcomes of this therefore the prevalence of ALTs were not discernable from this study.

Three ASD diagnostic instruments were employed throughout five studies: Mandell et al., (2012) used the Autism Diagnostic Interview- Revised (ADI-R) which they identified as the 'gold standard' diagnostic interview schedule for ASD although there is a paucity of research 
concerning its reliability for use with this population. The Diagnostic Interview for Social and Communication Disorders Version 11 (DISCO-11) is considered to have high agreement with ADI-R classification, in addition to excellent psychometric properties however schizophrenia is an exclusion criterion in the diagnostic algorithm (Waris et al., 2013). Waris et al. (2013) used this instrument in their sample of adolescents with schizophrenia, yet they did not make reference to any adaptations to the tool and reported on diagnostic prevalence despite the caveat for diagnosis. Prevalence of ALTs was also discernable from these assessments: more than half of participants fulfilled the diagnostic symptom profile for AS at the time of assessment, in contrast to the number of individuals who received a genuine diagnosis of AS based on evidence of its origins in childhood (11.1\%). Of interest, all participants were found to exhibit at least one of the principal symptoms of PDD in adolescence. The DISCO-11 was also used by Hallerback et al. (2012) but was adapted to omit questions pertaining to schizophrenia and this may have implications for the validity and comparability of their findings.

Diagnostic interviews based on DSM-IV diagnostic criteria were utilised by both Davidson et al. (2014) and Chang et al. (2003) however neither author identifies the specific diagnostic interview (e.g. SCID). The separate categorization of ASD and schizophrenia in the DSM-IV presents a similar obstacle in that there appears to be an "either-or" position regarding diagnosis of the two constructs however neither study delineates how they managed this complexity. Of note, Fraser et al. (2012) also employed DSM-IV criteria as a screening assessment using clinician judgment (rather than diagnostic interview) in order to identify potential ALTs. This was accompanied by professional training sessions which aimed to enhance clinician awareness, knowledge and understanding of ASD and co-morbidities; however, these sessions were not 
mandatory and the inter-rater reliability of the screening process was not formally assessed. Furthermore, they identified individuals with an existing diagnosis of ASD, which was previously assessed using the ADI, and potentially an additional ADOS assessment.

Sample size negatively impacted on the quality ratings of four studies. Both Matsuo et al. (2105) and Hallerback et al. (2012) had relatively small sample sizes when considering outpatient populations with psychosis as less than 100 participants may not be a truly representative sample (Chisholm et al., 2015). Whilst Waris and colleagues' (2013) sample size is considered small in terms of a prevalence study $(\mathrm{N}=18)$, it did include all the patients of rehabilitations units for adolescents with schizophrenia within a Hospital District in Finland. The sample size in Mandell et al.'s (2012) inpatient study was acceptable $(\mathrm{N}=123)$ however this represents less than half of the eligible individuals.

\section{Discussion}

Overall, the findings of this review demonstrate elevated prevalence rates of ASD at the diagnostic level and at the trait level in psychotic populations compared to the general population. The co-occurrence of psychosis and ALTs is evidently more frequent than ASD at the diagnostic level. The wide-ranging prevalence rates highlighted by this review are problematic in terms of estimating the actual prevalence rates, and may be in part attributable to the variability in measurement and methodology used across the studies. These findings provide evidence of symptomalogical overlap between the two disorders; however, the wide-ranging prevalence rates may reflect issues regarding the conceptualization of symptoms within current 
diagnostic classification systems. Both schizophrenia and ASD are considered to be chronic, multi-factorial disorders which include clinical presentations across a continuum of severity and disability. Issues pertaining to high heterogeneity within both constructs are therefore problematic for psychiatric classification systems which rely on the presence of specified clinical symptoms (Solomon et al., 2008). In addition to shared symptomatolgy and risk factors, genetic studies have highlighted direct and indirect links between ASD and schizophrenia (Hallerback et al., 2012). Phenotypic similarities between these two presentations illustrate an inherent problem regarding diagnosis, and can result in difficulties with differential diagnosis. Furthermore, exclusion criteria outlined in diagnostic categories may preclude the diagnosis of both disorders simultaneously.

As ASD is a developmental disorder which by definition is present from early childhood, it is essential to consider an individual's development history in order to discriminate between true ASD and ALTs which may currently map onto diagnostic criteria. Four of the six studies reporting on ASD diagnosis utilised developmental history to inform diagnosis via interviews with parents or family members known to the participant during childhood (Waris et al. 2013 ; Mandell et al. 2012; Hallerback et al. 2012; Fraser et al. 2012); however, both Davidson et al. (2014) and Chang et al. (2003) sought historical information from family members where possible. Reliance on retrospective information from family members has advantages in that they are likely to have the best knowledge of their child however it also has drawbacks which include the potential influence of recall bias. Childhood development is of further interest when considering the evidence suggesting that schizophrenia spectrum disorders may be more prevalent in children who meet the criteria for both PDD-NOS and Multiple Complex 
Developmental Disorder (MCDD) compared to Autistic Disorder ('classic autism'). Whilst the construct of MCDD is not currently recognized within psychiatric classification systems, it appears to offer a way of conceptualizing the subset of children whose complex neurodevelopmental symptom patterns traverse diagnostic boundaries between ASD and psychosis by exhibiting social functioning impairments and reality testing impairments (Cochran et al., 2013).

With the exception of Waris et al. (2013), the assessment of ALTs was of a cross-sectional nature whereby the current or recent presence of a symptom (e.g. within the past 6 months) was recorded although childhood presence was not explored. Nevertheless, their purpose was primarily to highlight individuals exhibiting symptoms consistent with ASD to allow for further assessment and possible diagnosis. All of the aforementioned ALT screening methods were observer-rated assessments which were informed by either a family member or a clinician known to the participant. Whilst observational tools are recognized as a valid way of screening for symptoms which are indicative of ASD, it is well documented that they are not capable of differentiating between negative symptoms of schizophrenia and ASD traits (Hallerback et al., 2012). The prevalence rate of diagnosed ASD reported by Fraser et al. (2012) related to diagnoses made by a pediatrician, psychiatrist or clinical psychologist prior to inclusion in the study. Despite concerns regarding the validity of observational assessments, their sample was from a youth mental health service therefore it is possible that a diagnosis of ASD was established prior to psychosis onset and would therefore be valid. 
Research attempting to understand the mechanisms underpinning the symptomalogical overlap between ASD and psychosis have identified substantive similarities and differences in several dimensions relevant to both disorders including cognitive dysfunction (memory, language and non-verbal reasoning), social functioning (including ToM), genetics and brain abnormalities. These phenotypic and genotypic similarities and vulnerabilities are suggestive of commonalities between the two constructs and therefore it appears plausible that some of these features may be responsible for the overlapping symptoms observed in both disorders for example ToM impairments underpinning social difficulties. It may therefore be conceived that the differences within the aforementioned dimensions may in part represent an interaction between aetiological and environmental components. It has been proposed that these overlaps may actually represent a more expansive set of overlaps across all neurodevelopmental disorders (Stone \& Iguchi, 2011).

Directionality may constitute another important factor in the association between the two disorders. It is well established that the development of psychotic illness is associated with aversive childhood and adulthood experiences such as bullying and trauma (Cunningham et al., 2015). Individuals with disorders such as ASD may be at an increased risk of victimization perhaps as a result of social and communication difficulties. Given that ASD has been identified as a risk factor for the development of psychosis (Van Roekel et al., 2010), it therefore seems possible that ASD symptoms such as impairments in social functioning may increase experiences of bullying, which in turn increases the risk of developing psychosis.

\subsection{Conclusions}


Overall, the results appear to consistently demonstrate that there is a higher prevalence of ALTs and ASD in psychosis populations compared to the general population in spite of methodological variance. Furthermore, the methodological shortcomings of studies imply an underrepresentation of ASD and ALTs prevalence within this population. Two studies are exceptions to this: Fraser et al. (2012) claim that their results may over-estimate the prevalence of ASD however do not explicitly clarify this viewpoint, whilst Hallerback et al. (2012) acknowledge the potential influence of gender in their predominantly male sample, given that ASDs are approximately four times more prevalent in males (Werling \& Geschwind, 2013) . Even so, it seems reasonable to conclude that ASD and ALTs are under-identified within this population, and therefore these outcomes are likely to serve as a minimum prevalence rate. The relationship between the two disorders appears to be maintained regardless of ASD diagnostic status.

The review highlighted a large difference between ASD prevalence rates prior to inclusion in studies and post-assessment, which parallels the findings of other studies in that the observed level of ASD was significantly higher than the number of people who carried that diagnosis prior to inclusion (Nylander \& Gillberg, 2001; Scragg \& Shah, 1994). This apparent discrepancy is somewhat more concerning when it is considered that participants across all studies were in contact with mental health services. Chang et al. (2003) is an exception to this as participants were first-visit attenders to their service. Davidson et al. (2014) suggests that there are a significant number of adults living with undiagnosed ASD within the UK. ASD is increasingly being assessed and diagnosed in adults and older adults although further research is necessary in order to develop appropriate instruments to assess these adult populations (Hallerbacket al., 2012; Mandell et al., 2015). Whilst more profound ASD difficulties are generally associated with 
an earlier age of diagnosis, higher-functioning individuals may not be so readily identified during childhood and therefore ASD may have remained undiagnosed until adolescence or adulthood following contact with mental health services (Fraser et al., 2012).

Some of the study samples were very specific (for example adolescent inpatients) and some of the measures lacked data on their reliability or validity for use with a psychosis population, therefore caution is warranted in the interpretation and generalization of results. Also, none of the studies utilized the most current diagnostic criteria; the DSM-5. Nevertheless, the core diagnostic criteria for schizophrenia have been retained from DSM-IV therefore it is conceivable that participants who received a DSM-IV diagnosis of schizophrenia are likely to have continued to fulfill the diagnostic criteria. In contrast to the previously separate subtypes of ASD outlined in the DSM-IV (as used by the studies in this review), the DSM-5 category of ASD includes the entire spectrum of presentations. Classification according to ASD subtypes made comparison across studies awkward therefore the term ASD was predominantly throughout this review in accordance with the DSM-5 classification. This seems appropriate given that ASD is a heterogeneous spectrum disorder and therefore there is natural variation even within the diagnostic criteria.

Davidson et al., (2014) posits that the concurrence between AS and psychotic disorders may actually represent misdiagnosis of AS rather than true co-morbidity, for example tactile hallucinations in schizophrenia may be understood as sensory processing issues in AS. Misdiagnosis of AS as psychosis may have significant implications for clients in terms of their 
treatment, for example the side effects of anti-psychotic medications may include impaired motor functioning, which could in turn potentially be considered as symptomatic of PDD. The presence of ASD symptoms since early childhood is essential for accurate diagnosis therefore the importance of gathering a detailed developmental history and the subsequent difficulties in obtaining this information was highlighted by a number of studies. Overlapping symptoms and confusion surrounding symptoms clearly presents a difficultly regarding differential diagnosis

This review has highlighted symptomalogical overlaps between these two constructs, which may go some way to contesting the current diagnostic conceptualization of these disorders as entirely separate conditions. That said, the degree of overlap at the ASD diagnostic level (provided diagnosis is informed by developmental history) continues to support a degree of diagnostic distinction between the two constructs (Stone \& Iguchi, 2011). The findings of this review encourage speculation as to shared aetiological and/or psychological mechanisms which may underpin the continua of both disorders.

\subsection{Implications}

This review has highlighted the need for large-scale epidemiological studies in order to establish accurate rates of co-occurrence of the two disorders, and revision of diagnostic criteria may be required in order to facilitate recognition of their co-occurrence (Davidson et al., 2014; Stahlberg et al., 2004). Discrepancy between ASD identification pre-and-post research studies highlights 
the need for better screening and identification of ALTs in individuals presenting with psychotic symptoms, however further research is required in order to enhance understanding of the overlapping and distinguishing features of ASD and psychosis in order to facilitate differential diagnosis. As diagnosis informs both psychological and pharmacological intervention, the gravity of appropriate diagnosis must be appreciated when the severe and debilitating sideeffects of anti-psychotic medication are considered. There is a clear need to better understand the relationship between the emergences of ALTs alongside psychotic phenomenon where traits have not been present during childhood therefore future research should aim to address this issue. Regardless of whether an individual meets the threshold for diagnosis or not, developing a better understanding of the complex relationship between these two conditions has significant clinical implications in terms of enhanced screening, diagnosis, early intervention and prognosis, ultimately in order to improve quality of life for affected individuals (Chisholm et al., 2015).

\subsection{Limitations}

This review is subject to certain limitations. Publication bias may mean that only published studies were included. One of the exclusion criteria for this review was a study sample from an ID population, which may have implications for the generalisability of results as ASD is often associated with ID. However, two studies assessed the prevalence of AS and therefore excluded participants with ID (as by definition, individuals with AS do not have ID) and two of the included studies had a minority of participants with ID, which may therefore improve the ecological validity of the findings of this review. Whilst the study explored sub-threshold ASD traits (ALTs), it did not take account of the literature pertaining to sub-threshold psychotic 
presentations such as At Risk Mental State (ARMS) criteria however the focus of the review was to ascertain the prevalence rates of ASD and ALTs within a psychosis population, whereas not all individuals who present with ARMS will develop a psychotic illness.

\section{Funding Information}

Funding was provided by The Queen's University of Belfast, School of Psychology, Belfast, Northern Ireland.

\section{Supplementary Appendix}

Kmet et al. (2004) Quality Assessment Criteria (criteria 5, 6, 7, $11 \& 12$ omitted)

\begin{tabular}{|c|c|c|c|c|c|}
\hline & Criteria & $\begin{array}{l}\text { Yes } \\
(2)\end{array}$ & $\begin{array}{l}\text { Partial } \\
\text { (1) }\end{array}$ & $\begin{array}{l}\text { No } \\
(0)\end{array}$ & N/A \\
\hline 1 & Question/ objective sufficiently described? & & & & \\
\hline 2 & Study design evident and appropriate? & & & & \\
\hline 3 & $\begin{array}{l}\text { Method of subject/ comparison group selection or source } \\
\text { of information/ input variables described and appropriate? }\end{array}$ & & & & \\
\hline 4 & $\begin{array}{l}\text { Subject (and comparison group, if applicable) } \\
\text { characteristics sufficiently described? }\end{array}$ & & & & \\
\hline 8 & $\begin{array}{l}\text { Outcome and (if applicable) exposure measure(s) well } \\
\text { defined and robust to measurement/ misclassification } \\
\text { bias? Means of assessment reported? }\end{array}$ & & & & \\
\hline 9 & Sample size appropriate? & & & & \\
\hline 10 & Analytic methods described/ justified and appropriate? & & & & \\
\hline 13 & Results reported in sufficient detail? & & & & \\
\hline 14 & Conclusions supported by the results? & & & & \\
\hline
\end{tabular}

Total Score: 


\section{References}

Askok, A.H., Baugh, J., Yeragani, V.K., 2012. Paul Eugen Bleuler and the origin of the term schizophrenia (Schizopreniegruppe). Indian Journal of Psychiatry, 54 (1), 95-96.

Bradley, E., Lunsky, Y., Palucka, A., Homitidis, S., 2011. Recognition of intellectual disabilities and autism in psychiatric inpatients diagnosed with schizophrenia and other psychotic disorders. Advances in Mental Health and Intellectual Disabilities, 5 (6), 4-18.

Brugha, T.S., McManus, S., Bankart, J., Scott, F., Purdon, S., Smith, J., Bebbington, P., Jenkins, R., Meltzer, H., 2011. Epidemiology of autism spectrum disorders in adults in the community in England. Archives of General Psychiatry, 68, 459-465.

Chang, H-L., Juang, Y-Y., Wang, W-T., Huang, C-I., Chen, C-Y., Hwang, Y-S., 2003. Screening for autism spectrum disorder in adult psychiatric outpatients in a clinic in Taiwan. General Hospital Psychiatry, 25, 284-288.

Chisholm, K., Lin, A., Abu-Akel, A., Wood, S.J., 2015. The association between autism and schizophrenia spectrum disorders: A review of eight alternate models of co-occurence. Neuroscience and Biobehavioural Reviews, 55, 173-183. 
Cochran, D.M., Dvir, Y., Frazier, J.A. 2013. “Autism-plus” Spectrum Disorders; Intersection with Psychosis and the Schizophrenia Spectrum. Child and Adolescent Psychiatric Clinics of North America, 22 (4), 609-628.

Cunningham, T., Hoy, K. \& Shannon, C., 2015. Does childhood bullying lead to the development of psychotic symptoms? A meta-analysis and review of prospective studies. Psychosis: Psychological, Social and Integrative Approaches, 8 (1), 48-59.

Davidson, C., Greenwood, N., Stansfield, A., Wright, S., 2014. Prevalence of Asperger syndrome among patients of an Early Intervention in Psychosis team. Early Intervention in Psychiatry, 8, 138-146.

Del Real, A., Brabban, A., Tiffin, P., 2010. Pervasive developmental disorder and early intervention in psychosis services: a survey of care coordinators' experiences. Early Intervention in Psychiatry, 4, 93-96.

Fraser, R., Cotton, S., Gentle, E., Angus, B., Allot, K., Thompson, A., 2012. Non-expert clinicians' detection of autistic traits among attenders of a youth mental health service. Early Intervention in Psychiatry, 6, 83-86.

Garety, P.A., Kuipers, E., Fowler, D., Freeman, D., Bebbington, P.E., 2001. A cognitive model of the positive symptoms of psychosis. Psychological Medicine, 31, 189-195. 
Hallerback, M.U., Lugnegard, T., Gillberg, C., 2012. Is autism spectrum disorder common in schizophrenia? Psychiatry Research, 198, 12-17.

Kmet, L.M., Lee, R.C., Cook, L.S., 2004. Standard Quality Assessment Criteria for Evaluating Primary Research Papers from a Variety of Fields. Alberta Heritage Foundation for Medical Research, Edmonton.

Konstantareas, M.M., Hewitt, T., 2001. Autistic Disorder and Schizophrenia: Diagnostic Overlaps. Journal of Autism and Developmental Disorders, 31 (1), 19-28

Mandell, D.S., Lawer, L.J., Branch, K., Brodkin, E.S., Healey, K., Witalec, R., Johnson, D.N., Gur, R.E., 2012. Prevalence and correlates of autism in a state psychiatric hospital. Autism, 16 (6), 557-567.

Matsuo, J., Kamio, Y., Takahashi, H., Ota, M., Teraishi, T., Hori, H., Nagashima, A., Takei, R., Higuchi, T., Motohashi, N., Kunugi, H., 2015. Autistic-Like Traits in Adult Patients with Mood Disorders and Schizophrenia. PLoS ONE, 10 (4), Art e0122711.

Moher, D., Liberati, A., Tetzlaff, J., Altman, D.G., 2009. Preferred Reporting Items for Systematic Reviews and Meta-Analyses: The PRISMA Statement. Journal of Clinical Epidemiology, 62, 1006-1012. 
Morrison, A.P., 2001. The interpretation of intrusions in psychosis: An integrative cognitive approach to hallucinations and delusions. Behavioural and Cognitive Psychotherapy, 29 (3), 257 276.

Nylander, L., Gillberg, C., 2001. Screening for autism spectrum disorders in adult psychiatric out-patients: a preliminary report. Acta Psychiatr Scand, 103, 428-434.

Nylander, L., Lugnegard, T., Hallerbäck, M.U., 2008. Autism Spectrum Disorders and Schizophrenia Spectrum Disorders in Adults- Is there a connection? A Literature Review and some suggestions for future clinical research. Clinical Neuropsychiatry, 5 (1), 43-54.

Padgett, F.E., Miltsiou,E., Tiffin, P.A., 2010. The co-occurrence of nonaffective psychosis and the pervasive developmental disorders: A systematic review. Journal of Intellectual and Developmental Disability, 35 (3), 187-198.

Raja, M., Azzoni, A., 2001. Asperger's disorder in the emergency psychiatric setting. General Hospital Psychiatry, 23, 285-293.

Rapoport, J., Chavez, A., Greenstein, D., Addington, A., Gogtay, N., 2009. Autism spectrum disorders and childhood-onset schizophrenia: clinical and biological contributions to a relation revisited. Journal of the American Academy of Child and Adolescent Psychiatry, 48 (1), 10-8.

Scragg, P., Shah, A., 1994. Prevalence of Asperger's syndrome in a secure hospital. British Journal of Psychiatry, 165, (5), 679-682. 
Skokauskas, N., Gallagher, L., 2010. Psychosis, affective disorders and anxiety in autistic spectrum disorder: prevalence and nosological considerations. Psychopathology, 43 (1), 8-16.

Solomon, M., Ozonoff, S., Carter, C., Caplan, R., 2008. Formal Thought Disorder and the Autism Spectrum: Relationship with Symptoms, Executive Control, and Anxiety. Journal of Autism and Developmental Disorders, 38, 1474-1484.

Sporn, A., Addington, A., Gogtay, N., Ordonez, A.E., Gornick, M., Clasen, L., Greenstein, D., Tossell, J.W., Gochman, P., Lenane, M., Sharp, W.S., Straub, R.E., Rapoport, J.L., 2004. Pervasive developmental disorder and childhood-onset schizophrenia: comorbid disorder or a phenotypic variant of a very early onset illness? Biological Psychiatry, 15;55(10), 989-994.

Stahlberg, O., Anckarsäter, H., Rastam, M., Gillberg, C., 2004. Bipolar disorder, schizophrenia, and other psychotic disorders in adults with childhood onset $\mathrm{AD} / \mathrm{HD}$ and/or autism spectrum disorders. Journal of Neural Transmission, 111, (7), 891-902.

Stone, W.S., Iguchi, L., 2011. Do Apparent Overlaps between Schizophrenia and Autistic Spectrum Disorders Reflect Superficial Similarities or Etiological Commonalities? North American Journal of Medical Sciences, 4 (3), 124-133. 
Van Roekel, E., Scholte, R.H.J., Didden, R., 2010. Bullying Among Adolescents With Autism Spectrum Disorders: Prevalence and Perception. Journal of Autism and Developmental Disorders, 40, 63-73.

Wairs, P., Lindberg, N., Kettunen, K., Tani, P., 2013. The relationship between Asperger's syndrome and schizophrenia in adolescence. European Child and Adolescent Psychiatry, 22, 217-223.

Werling, D.M., Geschwind, D.H., 2013. Sex differences in autism spectrum disorders. Current Opinion in Neurology, 26 (2), 146-153.

\section{Highlights}

- Rates of ASD and ASD traits are elevated in a psychosis population

- Despite overlaps, there remains a diagnostic distinction between the two disorders

- Large-scale epidemiological studies are required to ascertain rates of co-occurrence 